Published in final edited form as:

Contemp Clin Trials. 2019 June ; 81: 62-70. doi:10.1016/j.cct.2019.04.015.

\title{
Vitamin D supplementation for prevention of cancer: The D2d Cancer Outcomes (D2dCA) study
}

\author{
Ranee Chatterjee ${ }^{\mathrm{a}}$, John K Erban ${ }^{\mathrm{b}}$, Paul Fuss ${ }^{\mathrm{c}}{ }$, Rowena Dolor ${ }^{\mathrm{d}}$, Erin LeBlanc ${ }^{\mathrm{e}}$, Myrlene \\ Staten $^{\dagger}$, Patricia Sheehan ${ }^{9}$, Anastassios Pittas ${ }^{h}$, and D2d Research Group \\ aDivision of General Internal Medicine, 200 Morris Street, $3^{\text {rd }}$ Floor, Box 104427, Durham, NC \\ 27701, USA \\ bCancer Center, Tufts Medical Center, 800 Washington St, Box 245, Boston, MA 02111, USA \\ 'Division of Endocrinology, Tufts Medical Center, 800 Washington Street, Box 268, Boston, MA \\ 02111, USA \\ ${ }^{\mathrm{d} D i v i s i o n}$ of General Internal Medicine, 200 Morris Street, ${ }^{\text {rd }}$ Floor, Box 104427, Durham, NC \\ 27701, USA \\ eKaiser Permanente Center for Health Research NW, 3800 N Interstate, Portland, OR 97229, \\ USA \\ fKelly Government Services for the National Institute of Diabetes and Digestive and Kidney \\ Diseases, 6701 Democracy Boulevard, Room 6107, Bethesda, MD 20817, USA \\ 9Spaulding Rehabilitation Network, $3001^{\text {st }}$ Ave, Charlestown, MA 02129, USA \\ hDivision of Endocrinology, Tufts Medical Center, 800 Washington Street, Box 268, Boston, MA \\ 02111, USA
}

\begin{abstract}
Evidence on biological plausibility from mechanistic studies and data from observational studies suggest that vitamin D may be linked to risk of several types of cancer. However, evidence from clinical trials evaluating the effect of vitamin D supplementation on cancer risk is limited. The Vitamin D and Type 2 Diabetes (D2d) study is a multi-center, randomized, placebo-controlled clinical trial conducted to examine the causal relationship between oral vitamin D supplementation and development of diabetes among overweight adults with prediabetes. The D2d study provides a unique opportunity to assess the effect of vitamin D supplementation at a higher dose (4,000 IU/ day) than has been used in other clinical trials with cancer outcomes, in a population at higher than
\end{abstract}

corresponding author ranee.chatterjee@duke.edu.

Publisher's Disclaimer: This is a PDF file of an unedited manuscript that has been accepted for publication. As a service to our customers we are providing this early version of the manuscript. The manuscript will undergo copyediting, typesetting, and review of the resulting proof before it is published in its final citable form. Please note that during the production process errors may be discovered which could affect the content, and all legal disclaimers that apply to the journal pertain.

Role of the Funding Source: Under the terms of the cooperative agreement funding mechanism used by the NIH, representatives from the sponsoring institute (NIDDK) participated in the design and conduct of the study; interpretation of the data; preparation, review and approval of the manuscript; and the decision to submit the manuscript for publication.

Duality of Interest. No potential conflicts of interest relevant to this article were reported. 
average risk for cancer. This paper provides: (1) baseline characteristics of the D2d population included in the D2d cancer outcomes secondary study (D2dCA) and comparison to other large trials of vitamin D supplementation and cancer risk; (2) description of data that are being collected during the trial and the planned statistical analyses to test whether vitamin D supplementation at a dose of 4,000 IU/day has an effect on incident cancer overall, on incidence of certain types of cancer, and on incidence of precancerous lesions. Results of D2dCA will help guide future research and clinical recommendations related to vitamin $\mathrm{D}$ and cancer risk.

\section{Keywords}

vitamin D; cancer risk; D2d study; prediabetes

\section{INTRODUCTION}

Evidence on biological plausibility from mechanistic studies and data from observational studies suggest that vitamin D status may be linked to risk of several types of cancer.(1-19) However, whether vitamin D supplementation lowers risk of cancer is unknown. Vitamin D is an appealing approach for prevention of cancer because of its ease of administration and low cost. However, most studies reporting significant associations between vitamin D and cancer incidence are observational studies, which do not establish causality. Few large trials have been conducted to examine whether vitamin D supplementation influences risk of cancer, and many of these trials have significant limitations: relatively low dose of vitamin D; small sample size; short follow up time; limited target population (e.g., women only). (20-22) One trial in the U.S. tested the combined effects of 2,000 IU/day of vitamin $\mathrm{D}_{3}$ and $1,500 \mathrm{mg} /$ day of calcium compared to placebo on cancer risk in 2,303 post-menopausal women over 4 years of follow-up.(23) Women randomized to vitamin $\mathrm{D}_{3}$ had a $30 \%$ lower risk of incident cancer, which was nearly statistically significant (hazard ratio $0.70 ; 95 \% \mathrm{CI}$ 0.47, 1.02).(23) A post-hoc analysis of the Vitamin D Assessment (ViDA) study among 5,108 people from New Zealand found no difference in incidence of cancer with 100,000 IU/month of vitamin $\mathrm{D}_{3}$ compared to placebo.(24) More recently, in a cohort of 25,874 older adults, the VITamin D and OmegA-3 TriaL (VITAL) reported no effect of 2,000 IU/day of vitamin $\mathrm{D}_{3}$ supplementation on incident cancer.(25) An ongoing large trial of over 21,000 Australian adults 65-84 years old will assess the health effects, including cancer, of 60,000 $\mathrm{IU} /$ month of vitamin $\mathrm{D}_{3}$ vs placebo.(26)

While large trials have not shown an effect of vitamin D supplementation on risk of incident cancer, meta-analyses of earlier trials have shown significant reductions in cancer-related mortality with vitamin D supplementation. $(21,27)$ A reduction in cancer-associated mortality with 2,000 IU/day of vitamin D was also observed in the VITAL study in a posthoc analysis that excluded cancers which developed within the first one or two years.(25)

Given inconsistent results from published trials, further study is needed to determine the effects of vitamin D supplementation on cancer incidence and cancer-related mortality, especially in higher-risk populations. The Vitamin D and Type 2 Diabetes (D2d) study is a multi-center, randomized, placebo-controlled clinical trial conducted to examine the causal 
relationship between oral vitamin D supplementation and development of diabetes among overweight adults with prediabetes.(28) The D2d cancer outcomes secondary study (D2dCA) will assess the effect of 4,000 IU/day of vitamin D supplementation on incidence of cancer and precancerous lesions in the D2d population which is at higher risk for cancer than average.(29)

\section{METHODS}

\section{Overview of trial design and oversight}

D2d is a randomized, double-blind, placebo-controlled clinical trial conducted in 22 medical centers in the United States (www.d2dstudy.org/sites) to evaluate the safety and efficacy of oral administration of 4,000 IU/day of cholecalciferol (vitamin $\mathrm{D}_{3}$ ) vs. placebo in people with prediabetes who are followed for incident diabetes for approximately 3 years after randomization.(28) The D2d study is primarily supported by the National Institute of Diabetes and Digestive and Kidney Diseases (NIDDK) and the Office of Dietary Supplements (ODS) of the National Institutes of Health (NIH) through a U01 cooperative agreement to Tufts Medical Center (principal investigator A.G.P.) where the D2d Coordinating Center is based. D2dCA is a secondary study to D2d to test the hypothesis that, compared to placebo, high-dose (4,000 IU/day) oral vitamin D supplementation reduces risk of incident cancer and pre-cancerous lesions in a cohort of overweight adults with prediabetes who are also at high risk for cancer.(29)

The study is approved and monitored by an independent Data and Safety Monitoring Board and the Institutional Review Board of each collaborating clinical research site.

\section{Participants}

Target participants are adults at risk for diabetes (i.e., with prediabetes), defined by the American Diabetes Association (ADA) in 2010 (30), as meeting at least 2-out-of-3 of the following: fasting plasma glucose (FPG) $100-125 \mathrm{mg} / \mathrm{dL}$; 2-hour plasma glucose (2hPG) after a 75-gram glucose load 140-199 mg/dL; hemoglobin A1c (HbA1c) 5.7-6.4\%. The other inclusion criteria are: age $\geq 30$ years ( $\geq 25$ years for American Indians, Alaska Natives, Native Hawaiians, or other Pacific Islanders) and body mass index (BMI) of $24-42 \mathrm{~kg} / \mathrm{m}^{2}$ $\left(22.5-42 \mathrm{~kg} / \mathrm{m}^{2}\right.$ for Asians). Key exclusion criteria include any glycemic criterion in the diabetes range (30); use of medications approved for treatment of diabetes; hyperparathyroidism; nephrolithiasis; bariatric surgery; use of supplements with vitamin D or calcium over study limitation (1000 IU/day or $600 \mathrm{mg} /$ day respectively); medications or conditions that could interfere with absorption or metabolism of vitamin D; major cardiovascular disease; hypercalcemia; hypercalciuria; chronic kidney disease; and history of cancer (except for basal cell skin cancer) within the past 5 years. Treated prostate or welldifferentiated thyroid cancer not expected to require any treatment over the next 4 years are not exclusions. Blood 25-hydroxyvitamin D concentration is not an eligibility criterion. For a complete list of eligibility criteria, see the Supplementary Appendix. The recruitment process relied primarily upon the use of electronic health records to identify potentially eligible adults who then had an in-person screening visit and, if qualified, a second screening 
visit to determine final eligibility by measuring FPG, $2 \mathrm{hPG}$, and HbA1c at the study's central laboratory.(31)

\section{Intervention}

Participants were randomized to take a single soft-gel once daily that contained 4,000 IU of vitamin $\mathrm{D}_{3}$ or matching placebo. Randomization was blocked-stratified by site, body mass index (less than 30 or greater than or equal to $30 \mathrm{~kg} / \mathrm{m}^{2}$ ) and race (White or non-White). The dose of 4,000 IU daily was chosen to balance safety, by staying within the tolerable upper limit, as defined by the Institute of Medicine,(32) and efficacy in terms of obtaining a large difference in blood 25-hydroxyvitamin D concentration between the treatment and control groups.

The vitamin D and placebo pills are prepared by Tishcon Corporation and shipped to the drug distribution center (Veterans Affairs Cooperative Studies Program, Albuquerque, NM) in bulk where they are packaged into sealed, serially numbered bottles identical in appearance and weight, and shipped to each site for storage and distribution to participants. Both the manufacturer and drug distribution center perform quality control analyses on each lot; and the drug distribution center performs periodic potency testing of each batch to ensure the amount of vitamin D stays within specifications (3,600 to 4,800 IU) throughout the 2-year recommended shelf-life. Site staff dispenses the study pills to participants twice a year at each scheduled visit using an Interactive Web Response System that ensures correct treatment assignment according to the randomization code while maintaining blinding. Unless stopped for a safety reason, study treatment continues until the last study encounter, even after participants meet the primary study outcome of diabetes. Bottles with unused pills are returned at the next visit. Adherence is assessed by pill count as the percentage of pills taken in relation to the number that should have been taken. Participants are asked to refrain from using diabetes or weight-loss medications during the study and to limit the use of outside-of-study vitamin D to 1000 IU per day from all supplements, including multivitamins. To optimize safety, the study also limits calcium supplements to $600 \mathrm{mg}$ per day.

Participants have a study visit at month 3, month 6, and twice a year thereafter. Midway through the visits, an interim contact (by phone or email depending on each participant's preference) takes place to encourage adherence to the intervention and to evaluate for adverse event occurrence and changes to medical conditions, including cancer-related outcomes.

\section{Incident Cancer and Cancer Mortality Outcomes}

Throughout D2d, a new diagnosis of cancer is identified as part of a standard health questionnaire administered at each encounter (in-person visit or phone/email encounter, 4 times/year). The questionnaire includes three general questions: "Have you had any changes in your health? Have you seen a doctor or had any visit to a healthcare provider since your last visit? Have you had any medications changed or new medications added?" Further information is obtained for any positive response. Starting in July 2017, after recruitment was completed, all randomized participants are asked questions specific to cancer screening 
and any diagnoses of cancer since the beginning of the study ("Have you been told you have cancer? Have you had a colonoscopy? Have you had a skin mole or lesion removed or biopsied? Have you had a breast biopsy? Have you had a prostate biopsy?"). These questions are then repeated as part of the standard health questionnaire at each subsequent encounter. A self-report of cancer, endoscopic colorectal examination, or a biopsy is entered in the electronic data capture (EDC) system; and supporting medical records (including pathology and procedure reports) are obtained and provided to the Cancer Clinical Events Reviewer for adjudication. To ensure that all potential cancers are captured, the Coordinating Center also reviews all adverse events reported by participants to identify events reported as cancer or those that may "harbor cancer" (e.g., pancreatic mass). The Coordinating Center then requests that sites submit such events and supporting documentation for adjudication, if not previously submitted as part of the health- or cancer-specific questionnaires.

For each cancer outcome, the Cancer Clinical Events Reviewer, a board-certified oncologist who is unaware of the treatment assignment, adjudicates and confirms the following information: whether there is sufficient information for adjudication; the type of cancer and whether it is cancer or precancer; laterality (right origin of primary, left origin of primary, not applicable); date of diagnosis; grade for breast, colon/rectum, lung (primary), and pancreas (adenocarcinoma) cancers; Gleason score for prostate cancer; hormone receptor status (estrogen receptor, progesterone receptor, human epidermal growth factor receptor-2) for breast cancer; and date of diagnosis. Because history of cancer, other than basal cell skin cancer or well-differentiated thyroid cancer or prostate cancer not expected to need treatment within the past 5 years, is an exclusion criterion, a diagnosis of cancer is considered "new" unless there is sufficient evidence to be classified as "recurrent." If there is equivalent evidence, it is classified as "undetermined." From prostate and breast biopsies and all endoscopic colorectal examinations, the following precancerous lesions are adjudicated: high-grade prostatic intraepithelial neoplasia for prostate; atypical ductal hyperplasia (ADH) or atypical lobular hyperplasia (ALH) for breast; and adenomatous polyp for colorectal. Table 1 describes the data sources and outcomes collected. The D2dCA study does not collect data on cancer stage because: (1) the study lacks power to draw insight from analyses by stage; (2) procedures to stage cancer accurately may have differed by site, and therefore staging might have been incomplete.

In addition to incident cancer, information on cause of all deaths in D2d is being collected. All reports of death are confirmed with medical records or death certificates, which are collected by the sites and sent to the Coordinating Center. Cause of death is being adjudicated both by the Cardiovascular Disease adjudicator and by the Cancer Clinical Events adjudicator.

Recognizing that there may be smaller than expected numbers of incident cancer and cancerrelated deaths, we are currently exploring options to contact participants periodically by phone or email after study completion to continue collecting data on incident cancer and mortality for a longer period of time. 


\section{Covariates}

Information on potential confounders or effect modifiers (e.g., age, gender, tobacco use) was collected for all participants by self-report at the baseline visits, which began in November 2013. A questionnaire to assess family history of cancer in first-degree relatives was administered to all participants beginning in January 2018. Current medication use is being collected throughout the study. At study initiation, only certain medications were entered in the database, and this did not originally include aspirin; however, aspirin use is being collected in source documents. In July 2017, sites were asked to retrospectively review concomitant medications in source documents and enter aspirin use (for regular regimens only, not occasional use) into the database. Subsequently, information on aspirin use is entered at every encounter. Use of non-steroidal anti-inflammatory drugs is not entered into the database because the benefit-burden ratio and reliability of data would be low. The International Physical Activity Questionnaire is administered at baseline, month 6 and yearly thereafter in all participants.(33) The Multicultural Food Frequency Questionnaire is administered at baseline in all participants and at month 12 and month 36 visits in participants free of diabetes.(34) Weight and height are measured at baseline and at every visit to calculate BMI.

Blood 25-hydroxyvitamin D level at baseline is not an eligibility criterion for the following reasons: (1) the definition of 'optimal' 25-hydroxyvitamin D is controversial and no consensus exists; $(32,35-42)(2)$ to ensure that the study is as "pragmatic" as possible and results are generalizable to clinical practice; (3) blood 25-hydroxyvitamin D level varies by season (32) and it is an acute-phase response;(43-45) (4) baseline 25-hydroxyvitamin D level is an important treatment selection marker in the subgroup analyses, and to assess its performance, participants with a wide range of 25-hydroxyvitamin D must be enrolled.(46) The study plans to measure serum 25-hydroxyvitamin D level at baseline, month 12 and month 24. If there is available funding, serum 25-hydroxyvitamin D level will also be measured at month 36 and 48 .

The D2d cohort was recruited at a constant rate throughout the calendar year and cancer outcomes are captured 4 times/year; therefore, the potential for seasonal variability confounding the effect of vitamin D supplementation and cancer outcomes is low. All analyses will adjust for site, which approximates latitude at the participant's residence.

\section{Sample size calculations}

As an event-driven trial, the parent trial will continue until the required number of diabetes events is reached.(28) Based on national registries (e.g., Surveillance Epidemiology and End Results [SEER]), and based on the observed characteristics of the D2d participants, the expected incidence for common non-basal cell cancers (e.g., breast, colon,) for the age (60-64 years) and gender (45\% women) distribution for the D2d population is estimated to be 26.4 cases yearly, or approximately $1.1 \%$ per year. The incidence of cancer in the D2d overweight population with prediabetes is likely to be higher.(29) The parent study was powered based on the primary outcome of incident diabetes. Power calculations for the D2dCA study can be estimated based on predicted incidence of cancer in the placebo group (SEER data), fixed sample size of 2,423 participants, the median expected follow-up of 3 
years, and different scenarios for relative risk reduction of cancer between study groups (Table 2). For example, if yearly incidence of cancer in the placebo group is $1.5 \%$, at 3 years, the power to detect a $40 \%$ relative risk reduction in cancer incidence in the vitamin D group compared to placebo would be 0.65 .

Assumptions: 2,423 participants randomized to placebo or vitamin $D$ at 1:1 ratio; mean follow-up 36 months; $1.5 \%$ yearly incidence of composite cancer (excluding non-melanoma skin) in placebo arm; alpha $=0.05$

\section{Statistical Analyses}

Descriptive data will include means and standard deviations, medians, or percentages. Intention-to-treat analyses will compare groups defined by the randomization procedure and will include all participants and all events observed during the study, irrespective of adherence to assigned treatment. Follow-up time in the study will be calculated as time from randomization until the outcome of interest (cancer or precancer) is met, death, active withdrawal, or last encounter with available data. We will also conduct a "per-protocol" analysis that censors follow-up at the first time a participant did not follow the protocol; for example, stopped study pills or started out-of-study calcium or vitamin D supplements at doses above study limitations.

The main outcome for D2dCA is first diagnosis during D2d (i.e., since randomization) of any type of cancer (excluding non-melanoma skin cancers). Each participant with a new cancer will be counted only once. Two analyses for the primary outcome will be conducted: one analysis will include the entire cohort; another analysis will be within each gender (men, women) because the association between prediabetes/diabetes and cancer risk can differ by gender, and the effect of vitamin D on cancer risk may also differ by gender.(47, 48) A sensitivity analysis will be conducted after excluding cancers that were diagnosed within the first 6 months after randomization, as these cancers may be pre-existing and previously unrecognized.

Kaplan-Meier estimates will be plotted for each group. Cox proportional hazard models will be used to compare the hazard rate of incident cancer between the two groups.(49) The model will include group assignment as its main predictor variable. The variables (study site, BMI, and race) used to stratify the randomization will be included in the model. Additional Cox models will be evaluated, adjusting for other covariates of importance (e.g., history of cancer, smoking history, aspirin use). The $p$-value from the primary analysis will be based on the chi-square statistic from a likelihood ratio test obtained from proportional hazards models with and without the term for intervention arm. All randomized participants will be included in the analysis and no attempt will be made to impute missing data for participants with missed encounters. Additional analyses will be conducted for the most common types of cancer (e.g., breast, colorectal, prostate), though individual totals are likely to be very small.

Analyses will also be conducted for all precancers combined and for selected individual precancerous histologies (breast, colorectal adenomas, prostate) though individual totals are likely to be very small. (Table 1 ). 
There is some evidence, while not consistent, that vitamin D supplementation may increase the risk of prostate cancer; $(11,15)$ therefore, a sensitivity analysis in the entire cohort will be done where the primary outcome will be defined as all cancers but will exclude prostate cancer. Similarly, inconsistent associations have been found between vitamin D and risk of pancreatic cancer; $(18,19)$ and so a sensitivity analysis will be conducted after excluding cases of pancreatic cancer.

Subgroup Analyses.-Variability of response to vitamin D supplementation will be assessed and defined by key baseline variables: calcium supplement intake (none vs any); serum 25-hydroxyvitamin D concentration $(<12$ or $\geq 12 \mathrm{ng} / \mathrm{mL} ;<20$ or $\geq 20 \mathrm{ng} / \mathrm{mL}$; continuous), as serum levels could reflect total exposure to vitamin D sources, including sources outside of the intervention;(50) body mass index ( $<30$ or $>30 \mathrm{~kg} / \mathrm{m}^{2}$ ); age (median value); race (white vs. Black vs. other); ethnicity (Hispanic or non-Hispanic); glycemic risk by number of prediabetes criteria met (two or three criteria); history of cancer; smoking history (never or ever). Each analysis of participant subgroups will include a test for interaction, and effect modification will be claimed only if the test for interaction reaches statistical significance. No adjustment will be made for subgroup analyses.

Two-sided $p$-values less than 0.05 will be considered statistically significant. Statistical analyses will be conducted using SAS software, Version 9.4 (SAS Institute Inc., Cary, NC).

\section{BASELINE AND STUDY CHARACTERISTICS}

From November 2013 through February 2017, 7,133 people were assessed for eligibility. Of these, 2,423 were randomly assigned to vitamin $\mathrm{D}$ or placebo and formed the intention-totreat population of D2dCA.(51) The baseline characteristics for D2dCA and how this cohort compares to other large trials that have tested the effect of vitamin D supplementation on cancer risk are described in Table 3. Women (45\%) and non-White participants (36\%) are well-represented in D2dCA. Thirty-two percent of participants reported a family history of breast, colorectal, prostate, or lung cancer in a first-degree relative. Among participants reporting intake of outside-of-study supplements, mean vitamin D intake from supplements was $730 \mathrm{IU} /$ day; and mean calcium intake from supplements was $311 \mathrm{mg} /$ day. Data from the food frequency questionnaire are not currently available.

Compared to other trials testing the effect of vitamin D supplementation and cancer risk, $\mathrm{D} 2 \mathrm{dCA}$ is unique in its participant population, comprised of overweight/obese people with prediabetes (Table 3). By contrast, the recently reported VITAL study included $13 \%$ of participants with diabetes.(52) Compared to other studies, D2dCA has greater racial and ethnic diversity.(23, 24, 52-54) Additionally, compared to other studies, D2dCA is unique in the dose of vitamin $\mathrm{D}_{3}$ administered (i.e., higher) and in its frequent assessments of adherence and outcomes. $(23,52,53)$. Participants in D2dCA were similar to the VITAL study participants in baseline use of vitamin D and calcium supplements. $(24,52)$ 


\section{DISCUSSION}

The D2dCA provides a unique opportunity to assess the effect of vitamin D supplementation on risk of cancer and precancerous lesions in a population (overweight adults with prediabetes) at higher risk for cancer. The D2dCA has many strengths including detailed phenotyping of baseline characteristics, multiple time points of contact with participants to capture cancer events, and the higher dose of vitamin D compared to other vitamin D supplementation trials.(20-25) Although this population is at higher risk of cancer compared to other studies assessing the association between vitamin $\mathrm{D}$ and cancer risk, potential limitations of this study include low power to detect a significant association and the relatively short follow-up time.

\section{Mechanisms linking prediabetes to cancer risk}

Overweight/obesity and the conditions of prediabetes and diabetes have been associated with increased risk of cancer.(29, 55) However, for prostate cancer an inverse association has been described with a lower incidence of prostate cancer among people with diabetes.(47) In general, the associations between prediabetes/diabetes and cancer risk are thought to be linked though common non-modifiable and modifiable risk factors, particularly age, increased adiposity, and decreased physical activity. Additionally, there is evidence that hyperglycemia, hyperinsulinemia and adiposity (all of which are generally present in patients with prediabetes/diabetes) can promote carcinogenesis at the cellular level through a variety of mechanisms. Through direct effects or effects mediated through other molecular mediators including cytokines, adipokines, and hormonal pathways, the milieu of hyperglycemia, hyperinsulinemia and chronic inflammation can lead to DNA damage, mitogenesis, cancer cell proliferation, protection of cancer cells from apoptosis, invasion, and metastasis (Figure 1).(55, 56)

\section{Mechanisms linking vitamin $D$ to cancer risk}

There are plausible mechanisms linking vitamin D to reduced cancer risk. Vitamin D in converted in the liver to 25-hydroxyvitamin $\mathrm{D}$ and then to its most biologically active metabolite, calcitriol, in the kidney by 1-alpha hydroxylase. Calcitriol has been implicated in many disease processes, including cancer, and many extra-renal organs express 1-alpha hydroxylase, which may further influence risk of carcinogenesis within these organs.(57-59) Calcitriol acts as a steroid hormone by binding to vitamin D receptors (VDR) and affecting gene expression, either promoting or inhibiting gene transcription. The calcitriol-VDR complex has also been found to exert cellular effects via non-genomic pathways.(60) Most cell types have VDRs, and the binding of calcitriol to VDRs results in a wide variety of effects that differ by cell type. With regards to the association between calcitriol and cancer, VDRs are found in most types of malignant cells, and the putative anti-neoplastic effects of calcitriol are thought to be mediated through its binding with VDRs. Through in vitro and animal models, several anti-neoplastic mechanisms have been identified, including: promotion of apoptosis or autophagy of cells, promotion of cellular differentiation, regulation of cellular proliferation, inhibition of angiogenesis, and prevention of invasion of malignant cells. Additionally, calcitriol has been found to decrease inflammatory reactions through mechanisms including inhibition of the production of inflammatory cytokines and 
prostaglandins.(1-3) Vitamin D, through the anti-carcinogenic mechanisms described above, could counter-act the carcinogenic mechanisms promoted by the hyperglycemia, hyperinsulinemia and adiposity in patients with prediabetes (Figure 1). Finally, in addition to the direct genomic and non-genomic anti-carcinogenic effects of vitamin $\mathrm{D}$, if vitamin $\mathrm{D}$ has an impact on diabetes risk through lowering glucose and/or insulin levels, it may additionally have indirect effects by reducing the carcinogenic processes which are promoted in a diabetic environment.

\section{Review of observational studies and trials}

Most human studies reporting on the association between vitamin D and cancer incidence are observational studies, (4-19) which preclude a definitive assessment of cause and effect because residual confounding or reverse causation cannot be excluded. Several large trials have reported on the effect of vitamin D supplementation with or without calcium on risk of precancers or cancers with inconclusive results. $(23-25,54,61-65)$

In the Women's Health Initiative Calcium and Vitamin D (WHI CaD) Trial (vitamin $\mathrm{D}_{3} 400$ IU/day and calcium $1,000 \mathrm{mg} /$ day), there was no benefit of vitamin $\mathrm{D}$ on individual or total invasive cancer risk.(61-63) However, a reanalysis of participants within the WHI CaD study who did not take outside-of-study calcium and vitamin D supplements showed a significant reduction in total cancer risk and risk of breast cancer in the group randomized to calcium and vitamin $\mathrm{D}$, as well as a non-significant reduction in risk of colorectal cancer.(66) The Vitamin D and Colon Polyp study (vitamin D 1000 IU/day with or without calcium carbonate $1200 \mathrm{mg} /$ day) showed no significant benefit of vitamin D on colon polyp recurrence.(65) Two trials with combined vitamin D and calcium supplementation have been conducted on post-menopausal women in Nebraska. $(23,64)$ The earlier of the two trials demonstrated a reduced incidence of cancer for the participants in the calcium (1400-1500 $\mathrm{mg} /$ day) and vitamin D (1100 IU/day) arm compared to placebo (relative risk of $0.40 ; 95 \%$ CI: 0.20, 0.82); however, incident cancer was a secondary outcome.(64) The more recent trial by Lappe et al, designed with cancer as the primary outcome, provided highly encouraging but inconclusive evidence for an effect of vitamin D supplementation on cancer risk.(23) This trial randomized 2,303 women (mean age 65) to a combination of vitamin $\mathrm{D}_{3}$ $(2,000$ units/day) and calcium $(1,500 \mathrm{mg} /$ day $)$ or placebos and followed them for 4 years for incident cancer.(23) Risk of cancer was lower in the vitamin D/calcium vs. placebo group; however, the difference was not statistically significant (hazard ratio 0.70 ; $95 \% \mathrm{CI} 0.45$ to 1.02). Of additional interest, the achieved 25 -hydroxyvitamin $D$ level was inversely associated with cancer incidence $(p=0.03$, coef $=-0.017)$.(23) Specifically, compared with 25-hydroxyvitamin $\mathrm{D}$ level of $30 \mathrm{ng} / \mathrm{mL}$ as baseline, the estimated hazard ratio for cancer incidence for 25-hydroxyvitamin D levels between 30 and $55 \mathrm{ng} / \mathrm{ml}$ was 0.65 (CI, 0.44 , 0.97).(23) The study by Lappe et al was well conducted but there were several possible reasons for missing statistical significance (e.g., high baseline 25-hydroxyvitamin D, high intake of out-of-study vitamin D), as discussed by the authors. Secondary analyses of the earlier trial and of both trials combined, additionally combined with a volunteer cohort of similar participants, evaluated the association between vitamin D levels and cancer risk; and these analyses found lower risks of cancer with higher 25-hydroxyvitamin D levels. $(67,68)$ 
In a post-hoc analysis of the ViDA trial from New Zealand (oral vitamin $\mathrm{D}_{3}$ initial bolus dose of $200000 \mathrm{IU}$ and followed by 100,000 IU/month vs placebo), there was no difference between treatment arms in incidence of cancer.(24) Finally, the recently reported VITAL study evaluated the effects of vitamin D (2,000 IU/dau) and omega-3 fatty acids (1g/day) on incident cancer and cardiovascular disease as co-primary outcomes.(25) The incidence in cancer overall was not different between treatment arms; however, in pre-specified subgroup analyses, there was a significant interaction between vitamin D and baseline BMI; compared to placebo, those participants taking vitamin D who were in the lower BMI group $(<25 \mathrm{~kg} / \mathrm{m} 2)$ had a significant reduction in cancer incidence (hazard ratio: $0.76 ; 95 \%$ CI: $0.63,0.90)$. Additionally, compared to placebo there was a non-statistically significant reduction among Black participants taking vitamin D (hazard ratio: 0.77; 95\% CI: 0.59, 1.01) $(p$ for interaction=.21).(25) Also, in a post-hoc analysis assessing cancer mortality, excluding the first one or two years of cancer deaths, compared to placebo, there was a significant reduction in cancer mortality among those participants taking vitamin D.(25) This reduction in cancer-related mortality has also been reported in systematic reviews of trials that tested the effect of vitamin D supplementation on cancer-related mortality.(21, 27)

\section{Strengths}

The D2dCA has several strengths in its design and conduct, as follows: a study population (overweight adults with prediabetes) at higher risk of cancer; $(29,55,69)$ inclusion of both women and men; sizeable proportion of non-White participants; higher dose of vitamin D (expected to increase achieved 25-hydroxyvitamin D level) given daily (considered more physiologic than non-daily doses); $(24,25,61)$ robust methods to collect events through direct contact with participants and adjudicate for cancer and precancerous lesions. Beyond the primary question of the effect of vitamin D supplementation on cancer, D2dCA will also provide data on the incidence of cancer and precancerous lesions, as detected in routine clinical practice, in a modern cohort of adults with prediabetes.

\section{Limitations}

While the D2dCA has many strengths, there are certain limitations. In D2dCA, cancer outcomes and precancerous lesions are assessed as post-hoc hypotheses with an anticipated median follow-up of approximately 3 years, which is a relatively short period for development of cancer; longer-term follow-up may be needed to uncover an effect, if present. Cancer screening procedures (e.g., colonoscopy) in study participants may vary across sites, which may introduce risk of reporting bias. To guard against this potential pitfall, analyses will adjust for study site at randomization. Finally, the D2dCA cohort includes overweight patients with prediabetes, which may limit generalizability; however, overweight and prediabetes are very prevalent ( 86 million Americans are estimated to have prediabetes) and this group is considered at high risk for cancer.

\section{Conclusion}

Based on highly consistent data from longitudinal observational studies, supportive evidence from mechanistic studies, and encouraging but inconclusive data from randomized trials, the D2dCA study will utilize the strengths of the D2d study to contribute important data on 
causality by providing long-term clinical trial data regarding the role of vitamin D supplementation at a dose of 4,000 IU/day for prevention of cancer and precancerous lesions among participants with prediabetes who are at higher-than-average risk of cancer.

\section{Supplementary Material}

Refer to Web version on PubMed Central for supplementary material.

\section{Acknowledgements:}

The D2d investigators gratefully acknowledge the outstanding commitment and dedication of the D2d study participants. We would also like to thank Clare Il'Giovine for her assistance with the figure.

Funding/Support: The planning phase of D2d was funded by the National Institute of Diabetes and Digestive and Kidney Diseases (NIDDK) through a multicenter clinical study implementation planning grant (U34) to Tufts Medical Center in Boston, MA (U34DK091958; principal investigator A.G.P.). Planning was also supported in part by the Intramural Research Program of the NIDDK. The conduct of D2d is primarily supported by NIDDK and the Office of Dietary Supplements of the National Institutes of Health through the multicenter clinical study cooperative agreement (U01DK098245; principal investigator A.G.P.) to Tufts Medical Center where the D2d Coordinating Center is based. The U01 grant mechanism establishes the NIDDK project scientist (M.A.S.) as a member of the D2d Research Group. The study also received secondary funding from the American Diabetes Association (1-14-D2d-01; principal investigator A.G.P.). Educational materials are provided by the National Diabetes Education Program. No pharmaceutical manufacturers contributed to the planning, design or conduct of D2d. Study pills were purchased from an independent nutritional supplement manufacturing company that has no association with any members of the D2d Research Group. The D2d investigators and the NIDDK project scientist were responsible for the design and conduct of the study; collection, management, analysis, and interpretation of the data; preparation, review, and approval of the manuscript; and decision to submit the manuscript for publication.

\section{References}

1. Krishnan AV, Feldman D. Mechanisms of the anti-cancer and anti-inflammatory actions of vitamin D. Annu Rev Pharmacol Toxicol. 2011;51:311-36. [PubMed: 20936945]

2. Leyssens C, Verlinden L, Verstuyf A. Antineoplastic effects of 1,25(OH)2D3 and its analogs in breast, prostate and colorectal cancer. Endocr Relat Cancer. 2013;20(2):R31-47. [PubMed: 23319494]

3. Welsh J. Cellular and molecular effects of vitamin D on carcinogenesis. Arch Biochem Biophys. 2012;523(1):107-14. [PubMed: 22085499]

4. Yin L, Grandi N, Raum E, Haug U, Arndt V, Brenner H. Meta-analysis: Serum vitamin D and colorectal adenoma risk. Prev Med. 2011;53(1-2):10-6. [PubMed: 21672549]

5. Yin L, Grandi N, Raum E, Haug U, Arndt V, Brenner H. Meta-analysis: serum vitamin D and breast cancer risk. Eur J Cancer. 2010;46(12):2196-205. [PubMed: 20456946]

6. Wei MY, Garland CF, Gorham ED, Mohr SB, Giovannucci E. Vitamin D and prevention of colorectal adenoma: a meta-analysis. Cancer Epidemiol Biomarkers Prev. 2008;17(11):2958-69. [PubMed: 18990737]

7. Ma Y, Zhang P, Wang F, Yang J, Liu Z, Qin H. Association between vitamin D and risk of colorectal cancer: a systematic review of prospective studies. J Clin Oncol. 2011;29(28):3775-82. [PubMed: 21876081]

8. Gandini S, Boniol M, Haukka J, Byrnes G, Cox B, Sneyd MJ, et al. Meta-analysis of observational studies of serum 25-hydroxyvitamin D levels and colorectal, breast and prostate cancer and colorectal adenoma. Int J Cancer. 2011;128(6):1414-24. [PubMed: 20473927]

9. Touvier M, Chan DS, Lau R, Aune D, Vieira R, Greenwood DC, et al. Meta-analyses of vitamin D intake, 25-hydroxyvitamin D status, vitamin D receptor polymorphisms, and colorectal cancer risk. Cancer Epidemiol Biomarkers Prev. 2011;20(5):1003-16. [PubMed: 21378269]

10. Lee JE, Li H, Chan AT, Hollis BW, Lee IM, Stampfer MJ, et al. Circulating levels of vitamin D and colon and rectal cancer: the Physicians' Health Study and a meta-analysis of prospective studies. Cancer Prev Res (Phila). 2011;4(5):735-43. [PubMed: 21430073] 
11. Xu Y, Shao X, Yao Y, Xu L, Chang L, Jiang Z, et al. Positive association between circulating 25hydroxyvitamin D levels and prostate cancer risk: new findings from an updated meta-analysis. J Cancer Res Clin Oncol. 2014;140(9):1465-77. [PubMed: 24838848]

12. Lai GY, Wang JB, Weinstein SJ, Parisi D, Horst RL, McGlynn KA, et al. Association of 25Hydroxyvitamin D with Liver Cancer Incidence and Chronic Liver Disease Mortality in Finnish Male Smokers of the ATBC Study. Cancer Epidemiol Biomarkers Prev. 2018.

13. Yan L, Gu Y, Luan T, Miao M, Jiang L, Liu Y, et al. Associations between serum vitamin D and the risk of female reproductive tumors: A meta-analysis with trial sequential analysis. Medicine (Baltimore). 2018;97(15):e0360. [PubMed: 29642181]

14. McCullough ML, Zoltick ES, Weinstein SJ, Fedirko V, Wang M, Cook NR, et al. Circulating Vitamin D and Colorectal Cancer Risk: An International Pooling Project of 17 Cohorts. J Natl Cancer Inst. 2018.

15. Batai K, Murphy AB, Ruden M, Newsome J, Shah E, Dixon MA, et al. Race and BMI modify associations of calcium and vitamin D intake with prostate cancer. BMC Cancer. 2017;17(1):64. [PubMed: 28103838]

16. Budhathoki S, Hidaka A, Yamaji T, Sawada N, Tanaka-Mizuno S, Kuchiba A, et al. Plasma 25hydroxyvitamin D concentration and subsequent risk of total and site specific cancers in Japanese population: large case-cohort study within Japan Public Health Center-based Prospective Study cohort. BMJ. 2018;360:k671. [PubMed: 29514781]

17. Garland CF, Gorham ED. Dose-response of serum 25-hydroxyvitamin D in association with risk of colorectal cancer: A meta-analysis. J Steroid Biochem Mol Biol. 2017;168:1-8. [PubMed: 27993551]

18. Stolzenberg-Solomon RZ, Jacobs EJ, Arslan AA, Qi D, Patel AV, Helzlsouer KJ, et al. Circulating 25-hydroxyvitamin D and risk of pancreatic cancer: Cohort Consortium Vitamin D Pooling Project of Rarer Cancers. Am J Epidemiol. 2010;172(1):81-93. [PubMed: 20562185]

19. Zhang X, Huang XZ, Chen WJ, Wu J, Chen Y, Wu CC, et al. Plasma 25-hydroxyvitamin D levels, vitamin D intake, and pancreatic cancer risk or mortality: a meta-analysis. Oncotarget. 2017;8(38): 64395-406. [PubMed: 28969079]

20. Bjelakovic G, Gluud LL, Nikolova D, Whitfield K, Krstic G, Wetterslev J, et al. Vitamin D supplementation for prevention of cancer in adults. Cochrane Database Syst Rev. 2014(6):CD007469. [PubMed: 24953955]

21. Keum N, Giovannucci E. Vitamin D supplements and cancer incidence and mortality: a metaanalysis. Br J Cancer. 2014;111(5):976-80. [PubMed: 24918818]

22. Goulao B, Stewart F, Ford JA, MacLennan G, Avenell A. Cancer and vitamin D supplementation: a systematic review and meta-analysis. Am J Clin Nutr. 2018;107(4):652-63. [PubMed: 29635490]

23. Lappe J, Watson P, Travers-Gustafson D, Recker R, Garland C, Gorham E, et al. Effect of Vitamin $\mathrm{D}$ and Calcium Supplementation on Cancer Incidence in Older Women: A Randomized Clinical Trial. JAMA. 2017;317(12):1234-43. [PubMed: 28350929]

24. Scragg R, Khaw KT, Toop L, Sluyter J, Lawes CMM, Waayer D, et al. Monthly High-Dose Vitamin D Supplementation and Cancer Risk: A Post Hoc Analysis of the Vitamin D Assessment Randomized Clinical Trial. JAMA Oncol. 2018;4(11):e182178. [PubMed: 30027269]

25. Manson JE, Cook NR, Lee IM, Christen W, Bassuk SS, Mora S, et al. Vitamin D Supplements and Prevention of Cancer and Cardiovascular Disease. N Engl J Med. 2018.

26. Neale RE, Armstrong BK, Baxter C, Duarte Romero B, Ebeling P, English DR, et al. The D-Health Trial: A randomized trial of vitamin $\mathrm{D}$ for prevention of mortality and cancer. Contemp Clin Trials. 2016;48:83-90. [PubMed: 27086041]

27. Bjelakovic G, Gluud LL, Nikolova D, Whitfield K, Wetterslev J, Simonetti RG, et al. Vitamin D supplementation for prevention of mortality in adults. Cochrane Database Syst Rev. 2014(1):CD007470. [PubMed: 24414552]

28. Pittas AG, Dawson-Hughes B, Sheehan PR, Rosen CJ, Ware JH, Knowler WC, et al. Rationale and design of the Vitamin D and Type 2 Diabetes (D2d) study: a diabetes prevention trial. Diabetes Care. 2014;37(12):3227-34. [PubMed: 25205139]

29. Huang Y, Cai X, Qiu M, Chen P, Tang H, Hu Y, et al. Prediabetes and the risk of cancer: a metaanalysis. Diabetologia. 2014;57(11):2261-9. [PubMed: 25208757] 
30. American Diabetes Association. Diagnosis and classification of diabetes mellitus. Diabetes Care. 2010;33 Suppl 1:S62-9. [PubMed: 20042775]

31. Aroda V SP, Vickery E, Staten M, LeBlanc E, Phillips L, Brodsky I, Chadha C, Chatterjee R, Ouellette M, Desouza C, Pittas A.. Accepted for publication by Clinical Trials: Journal of the Society for Clinical Trials, February 2019. Establishing an electronic health record-supported approach for outreach to and recruitment of persons at high risk of type 2 diabetes in clinical trials: the vitamin D and type 2 diabetes (D2d) study experience. Clinical Trials. 2019.

32. Institute of Medicine Dietary Reference Intakes for Calcium and Vitamin D. Washington, DC: The National Academies Press; 2011.

33. Hagstromer M, Oja P, Sjostrom M. The International Physical Activity Questionnaire (IPAQ): a study of concurrent and construct validity. Public Health Nutr. 2006;9(6):755-62. [PubMed: 16925881]

34. Tucker KL, Bianchi LA, Maras J, Bermudez OI. Adaptation of a food frequency questionnaire to assess diets of Puerto Rican and non-Hispanic adults. Am J Epidemiol. 1998;148(5):507-18. [PubMed: 9737563]

35. Holick MF, Binkley NC, Bischoff-Ferrari HA, Gordon CM, Hanley DA, Heaney RP, et al. Evaluation, treatment, and prevention of vitamin D deficiency: an Endocrine Society clinical practice guideline. J Clin Endocrinol Metab. 2011;96(7):1911-30. [PubMed: 21646368]

36. Engelman CD. Vitamin d recommendations: the saga continues. J Clin Endocrinol Metab. 2011;96(10):3065-6. [PubMed: 21976747]

37. Aloia JF. The 2011 report on dietary reference intake for vitamin d: where do we go from here? J Clin Endocrinol Metab. 2011;96(10):2987-96. [PubMed: 21795456]

38. Rosen CJ, Abrams SA, Aloia JF, Brannon PM, Clinton SK, Durazo-Arvizu RA, et al. IOM Committee Members Respond to Endocrine Society Vitamin D Guideline. J Clin Endocrinol Metab. 2012.

39. Holick MF, Binkley NC, Bischoff-Ferrari HA, Gordon CM, Hanley DA, Heaney RP, et al. Guidelines for Preventing and Treating Vitamin D Deficiency and Insufficiency Revisited. J Clin Endocrinol Metab. 2012.

40. Maxmen A. Vitamin D on Trial. The Scientist. 2012.

41. Sattar N, Welsh P, Panarelli M, Forouhi NG. Increasing requests for vitamin D measurement: costly, confusing, and without credibility. Lancet. 2012;379(9811):95-6. [PubMed: 22243814]

42. American Geriatrics Society Workgroup on Vitamin DSfOA. Recommendations abstracted from the American Geriatrics Society Consensus Statement on vitamin D for Prevention of Falls and Their Consequences. Journal of the American Geriatrics Society. 2014;62(1):147-52. [PubMed: 24350602]

43. Reid D, Toole BJ, Knox S, Talwar D, Harten J, O'Reilly DS, et al. The relation between acute changes in the systemic inflammatory response and plasma 25-hydroxyvitamin D concentrations after elective knee arthroplasty. Am J Clin Nutr. 2011;93(5):1006-11. [PubMed: 21411617]

44. Louw JA, Werbeck A, Louw ME, Kotze TJ, Cooper R, Labadarios D. Blood vitamin concentrations during the acute-phase response. Crit Care Med. 1992;20(7):934-41. [PubMed: 1617986]

45. Waldron JL, Ashby HL, Cornes MP, Bechervaise J, Razavi C, Thomas OL, et al. Vitamin D: a negative acute phase reactant. J Clin Pathol. 2013;66(7):620-2. [PubMed: 23454726]

46. Janes H, Pepe MS, Bossuyt PM, Barlow WE. Measuring the performance of markers for guiding treatment decisions. Ann Intern Med. 2011;154(4):253-9. [PubMed: 21320940]

47. Bansal D, Bhansali A, Kapil G, Undela K, Tiwari P. Type 2 diabetes and risk of prostate cancer: a meta-analysis of observational studies. Prostate Cancer Prostatic Dis. 2013;16(2):151-8, S1. [PubMed: 23032360]

48. Ohkuma T, Peters SAE, Woodward M. Sex differences in the association between diabetes and cancer: a systematic review and meta-analysis of 121 cohorts including 20 million individuals and one million events. Diabetologia. 2018;61(10):2140-54. [PubMed: 30027404]

49. Cox D. Regression Models and Life Tables (with Discussion). J RStatist Soc. 1972, Series B(34): 187-220. 
50. Grant WB, Boucher BJ, Bhattoa HP, Lahore H. Why vitamin D clinical trials should be based on 25-hydroxyvitamin D concentrations. J Steroid Biochem Mol Biol. 2018;177:266-9. [PubMed: 28842142]

51. LeBlanc ES, Pratley RE, Dawson-Hughes B, Staten M, Sheehan P, Lewis MR, et al. Baseline characteristics of the vitamin D and type 2 diabetes (D2d) study: A contemporary prediabetes cohort that will inform diabetes prevention efforts. Diabetes Care. 2018.

52. Bassuk SS, Manson JE, Lee IM, Cook NR, Christen WG, Bubes VY, et al. Baseline characteristics of participants in the VITamin D and OmegA-3 TriaL (VITAL). Contemp Clin Trials. 2016;47:235-43. [PubMed: 26767629]

53. Jackson RD, LaCroix AZ, Cauley JA, McGowan J. The Women's Health Initiative calcium-vitamin D trial: overview and baseline characteristics of participants. Ann Epidemiol. 2003,13(9 Suppl):S98-106. [PubMed: 14575942]

54. Trivedi DP, Doll R, Khaw KT. Effect of four monthly oral vitamin D3 (cholecalciferol) supplementation on fractures and mortality in men and women living in the community: randomised double blind controlled trial. BMJ. 2003;326(7387):469. [PubMed: 12609940]

55. Giovannucci E, Harlan DM, Archer MC, Bergenstal RM, Gapstur SM, Habel LA, et al. Diabetes and cancer: a consensus report. Diabetes Care. 2010;33(7):1674-85. [PubMed: 20587728]

56. Shlomai G, Neel B, LeRoith D, Gallagher EJ. Type 2 Diabetes Mellitus and Cancer: The Role of Pharmacotherapy. J Clin Oncol. 2016;34(35):4261-9. [PubMed: 27903154]

57. Zehnder D, Bland R, Williams MC, McNinch RW, Howie AJ, Stewart PM, et al. Extrarenal expression of 25-hydroxyvitamin d(3)-1 alpha-hydroxylase. J Clin Endocrinol Metab. 2001;86(2): 888-94. [PubMed: 11158062]

58. Hobaus J, Thiem U, Hummel DM, Kallay E. Role of calcium, vitamin D, and the extrarenal vitamin D hydroxylases in carcinogenesis. Anticancer Agents Med Chem. 2013;13(1):20-35. [PubMed: 23094918]

59. King AN, Beer DG, Christensen PJ, Simpson RU, Ramnath N. The vitamin D/CYP24A1 story in cancer. Anticancer Agents Med Chem. 2010;10(3):213-24. [PubMed: 20184548]

60. Vuolo L, Di Somma C, Faggiano A, Colao A. Vitamin D and cancer. Front Endocrinol (Lausanne). 2012;3:58. [PubMed: 22649423]

61. Design of the Women's Health Initiative clinical trial and observational study. The Women's Health Initiative Study Group. Control Clin Trials. 1998;19(1):61-109. [PubMed: 9492970]

62. Wactawski-Wende J, Kotchen JM, Anderson GL, Assaf AR, Brunner RL, O'Sullivan MJ, et al. Calcium plus vitamin D supplementation and the risk of colorectal cancer. N Engl J Med. 2006;354(7):684-96. [PubMed: 16481636]

63. Chlebowski RT, Johnson KC, Kooperberg C, Pettinger M, Wactawski-Wende J, Rohan T, et al. Calcium plus vitamin D supplementation and the risk of breast cancer. J Natl Cancer Inst. 2008;100(22):1581-91. [PubMed: 19001601]

64. Lappe JM, Travers-Gustafson D, Davies KM, Recker RR, Heaney RP. Vitamin D and calcium supplementation reduces cancer risk: results of a randomized trial. Am J Clin Nutr. 2007;85(6): 1586-91. [PubMed: 17556697]

65. Baron JA, Barry EL, Mott LA, Rees JR, Sandler RS, Snover DC, et al. A Trial of Calcium and Vitamin D for the Prevention of Colorectal Adenomas. N Engl J Med. 2015;373(16):1519-30. [PubMed: 26465985]

66. Bolland MJ, Grey A, Gamble GD, Reid IR. Calcium and vitamin D supplements and health outcomes: a reanalysis of the Women's Health Initiative (WHI) limited-access data set. Am J Clin Nutr. 2011;94(4):1144-9. [PubMed: 21880848]

67. McDonnell SL, Baggerly C, French CB, Baggerly LL, Garland CF, Gorham ED, et al. Serum 25Hydroxyvitamin D Concentrations $>/=40 \mathrm{ng} / \mathrm{ml}$ Are Associated with $>65 \%$ Lower Cancer Risk: Pooled Analysis of Randomized Trial and Prospective Cohort Study. PLoS One. 2016;11(4):e0152441. [PubMed: 27049526]

68. McDonnell SL, Baggerly CA, French CB, Baggerly LL, Garland CF, Gorham ED, et al. Breast cancer risk markedly lower with serum 25 -hydroxyvitamin $D$ concentrations $>/=60 \mathrm{vs}<20 \mathrm{ng} / \mathrm{ml}$ $(150 \mathrm{vs} 50 \mathrm{nmol} / \mathrm{L})$ : Pooled analysis of two randomized trials and a prospective cohort. PLoS One. 2018;13(6):e0199265. [PubMed: 29906273] 
69. Shikata K, Ninomiya T, Kiyohara Y. Diabetes mellitus and cancer risk: review of the epidemiological evidence. Cancer Sci. 2013;104(1):9-14. [PubMed: 23066889] 


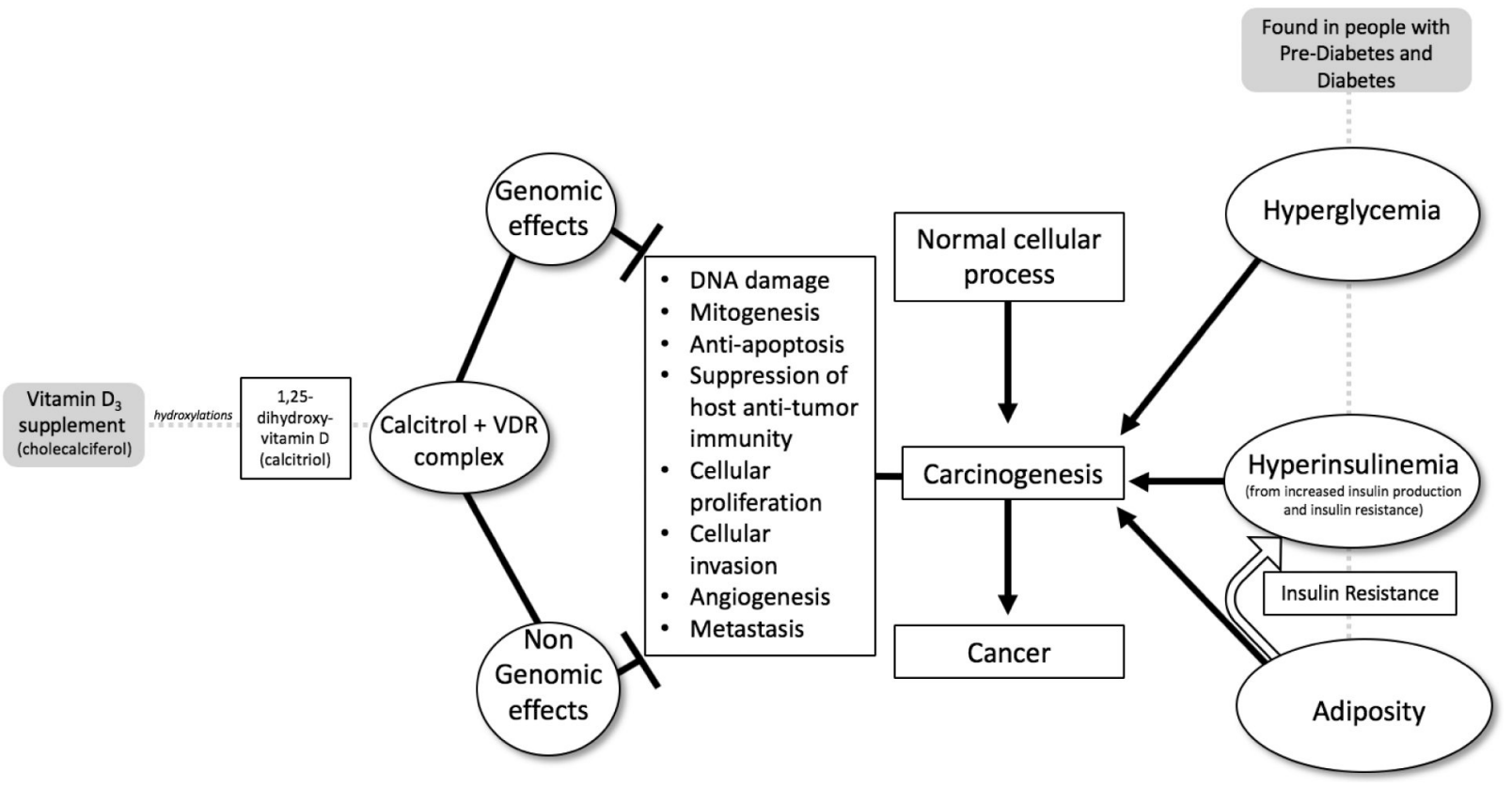

Figure 1.

Mechanisms of associations between prediabetes, vitamin D, and cancer risk 
Table 1.

Primary data sources and cancer outcomes for D2dCA

\begin{tabular}{|l|}
\hline Data sources \\
\hline Prostate biopsies \\
\hline Breast biopsies \\
\hline Skin biopsies \\
\hline Colonoscopy reports \\
\hline Self-reported cancer or possible cancer diagnoses \\
\hline Adjudicated cancer outcomes \\
\hline Prostate \\
\hline Breast (includes ductal carcinoma in-situ [DCIS]) \\
\hline Melanoma (including melanoma-in-situ) \\
\hline Colon or rectum \\
\hline Blood (1 leukemia, and myeloma) \\
\hline Lymphoma \\
\hline Brain \\
\hline Cervical \\
\hline Endometrium \\
\hline Gastric \\
\hline Liver \\
\hline Lung \\
\hline Neuroendocrine \\
\hline Ovary \\
\hline Pancreas (adenocarcinoma) \\
\hline Thyroid \\
\hline Other cancer \\
\hline Adjudicated precancers \\
\hline Prostate (high-grade prostatic intraepithelial neoplasia) \\
\hline Breast (atypical ductal hyperplasia [ADH], atypical lobular hyperplasia [ALH]) \\
\hline Colorectal adenomatous polyp \\
\hline
\end{tabular}


Table 2.

Power for possible scenarios of risk reduction in cancer incidence in D2dCA

\begin{tabular}{|r|r|}
\hline $\begin{array}{l}\text { Relative risk reductionfor } \\
\text { vitamin D vs placebo (\%) }\end{array}$ & Power \\
\hline $60 \%$ & 0.964 \\
\hline $55 \%$ & 0.923 \\
\hline $50 \%$ & 0.856 \\
\hline $45 \%$ & 0.762 \\
\hline $40 \%$ & 0.647 \\
\hline
\end{tabular}


Table 3.

Baseline characteristics and study intervention of D2dCA participants compared with other large trials of vitamin D and cancer

\begin{tabular}{|c|c|c|c|c|}
\hline & $\begin{array}{c}\text { D2dCA } \\
(\mathbf{n}=\mathbf{2 , 4 2 3})\end{array}$ & $\begin{array}{l}\text { Lappe et al }(23) \\
\quad(n=2,303)\end{array}$ & $\begin{array}{l}\text { VITAL }(52) \\
(n=25,874)\end{array}$ & $\begin{array}{l}\operatorname{ViDA}(24) \\
(n=5,108)\end{array}$ \\
\hline \multicolumn{5}{|l|}{ Characteristic } \\
\hline $\begin{array}{l}\text { Vitamin D Intervention (and } \\
\text { other components if } \\
\text { applicable) }\end{array}$ & $\begin{array}{l}\mathrm{D}_{3}, 4,000 \mathrm{IU} / \text { day vs. } \\
\text { placebo }\end{array}$ & $\begin{array}{c}\mathrm{D}_{3}, 2,000 \mathrm{IU} / \text { day } \\
\text { and calcium } 1500 \\
\text { mg/day vs. } \\
\text { placebos }\end{array}$ & $\begin{array}{l}\mathrm{D}_{3}, 2,000 \mathrm{IU} / \text { day } \\
\text { vs. placebo (in a } \\
2 \times 2 \text { factorial } \\
\text { design with marine } \\
\text { omega-3 fatty acid } \\
1 \mathrm{~g} / \text { dsupplements) }\end{array}$ & $\begin{array}{l}\mathrm{D}_{3}, 200,000 \mathrm{IU} \text { bolus followed by } \\
100,000 \mathrm{IU} / \mathrm{month} \text { vs. placebo }\end{array}$ \\
\hline $\begin{array}{l}\text { Outcome definition (post-hoc } \\
\text { or primary) }\end{array}$ & $\begin{array}{l}\text { Incidence of all } \\
\text { cancers, excluding } \\
\text { non-melanoma skin } \\
\text { cancers (post-hoc) }\end{array}$ & $\begin{array}{l}\text { Incidence of all } \\
\text { cancers, excluding } \\
\text { non-melanoma } \\
\text { skin cancers } \\
\text { (primary) }\end{array}$ & $\begin{array}{l}\text { Incidence of all } \\
\text { cancers (primary) }\end{array}$ & Incidence of all cancers (post-hoc) \\
\hline $\begin{array}{l}\text { Frequency of outcome } \\
\text { assessment (method) }\end{array}$ & $\begin{array}{l}4 \text { times/year: } 2 \text { times/ } \\
\text { year in-person; } 2 \\
\text { times/year by phone/ } \\
\text { email (questionnaire) }\end{array}$ & $\begin{array}{l}2 \text { times/year, in- } \\
\text { person } \\
\text { (questionnaire) }\end{array}$ & $\begin{array}{l}\text { Month 6, year 1, } \\
\text { then yearly (mail- } \\
\text { in questionnaires) }\end{array}$ & Monthly (mail-in questionnaires) \\
\hline Median follow-up, years & 3 (anticipated) & 4 & 5.3 & 3.3 \\
\hline Target population & $\begin{array}{l}\text { At risk for diabetes, } \\
\text { men or women age } \\
\geq 30 \text { years ( } \geq 25 \text { years } \\
\text { for people of the } \\
\text { following } \\
\text { groups:American } \\
\text { Indian, Alaska Native, } \\
\text { Native Hawaiian, or } \\
\text { other Pacific Islander) }\end{array}$ & $\begin{array}{c}\text { Healthy, post- } \\
\text { menopausal } \\
\text { women age } \geq 55 \\
\text { years }\end{array}$ & $\begin{array}{l}\text { Healthy men age } \\
\geq 50 \text { or women age } \\
\geq 55 \text { years }\end{array}$ & $\begin{array}{c}\text { Healthy men or women, aged } 50-84 \\
\text { years }\end{array}$ \\
\hline Mean age, years & 59.4 & 65.2 & 67.1 & 65.9 \\
\hline Women, no. (\%) & $1086(44.8)$ & $2303(100)$ & $13,081(50.6)$ & $2140(41.9)$ \\
\hline White race, no. (\%) & $1616(66.7)$ & $2291(99.5)$ & $18,047(71.3)$ & $4253(83.3)$ \\
\hline $\begin{array}{l}\text { Mean body mass index, } \\
\mathrm{kg} / \mathrm{m}^{2}\end{array}$ & 32.0 & $\sim 30$ & 28.1 & 28.5 \\
\hline $\begin{array}{l}\text { Self-reported family history } \\
\text { of cancer, } \%\end{array}$ & $\begin{array}{c}\text { Colorectal } \\
8.6 \% ; \text { Breast cancer } \\
\text { (women only), } 15.4 \% \text {; } \\
\text { Prostate cancer (men } \\
\text { only) } 10.3 \% ; \text { Lung } \\
\text { cancer } 11.0 \%\end{array}$ & Not available & $\begin{array}{c}\text { Colorectal } 13.4 \% \text {; } \\
\text { Breast cancer } \\
\text { (women only) } \\
17.7 \% \text {; Prostate } \\
\text { cancer (menonly) } \\
15.2 \% \text {; Lung } \\
\text { cancer } 14.5 \%\end{array}$ & Not available \\
\hline \multicolumn{5}{|l|}{ Smoking, \% } \\
\hline Never & 58.7 & $\sim 67$ & 51.7 & 51.0 \\
\hline Former & 34.9 & Not available & 41.1 & 42.5 \\
\hline Current & 6.5 & $\sim 6$ & 7.2 & 6.3 \\
\hline $\begin{array}{l}\text { Vitamin D supplements } \\
\text { outside-of-study allowed, } \\
\text { IU/day }\end{array}$ & 1000 & 800 & 800 & $\begin{array}{c}600 \text { if age } 50-70 \text { years; } 800 \text { if age } \\
71-84 \text { years }\end{array}$ \\
\hline $\begin{array}{l}\text { Participants taking vitamin } \\
\text { D supplements, \% }\end{array}$ & 42.6 & Not available & 42.6 & 8.0 \\
\hline $\begin{array}{l}\text { Vitamin D intake from } \\
\text { supplements among }\end{array}$ & 730 & $\sim 700$ & Not available & Not available \\
\hline
\end{tabular}




\begin{tabular}{|c|c|c|c|c|}
\hline & $\begin{array}{c}\text { D2dCA } \\
(\mathrm{n}=\mathbf{2 , 4 2 3})\end{array}$ & $\begin{array}{l}\text { Lappe et al(23) } \\
\quad(\mathrm{n}=\mathbf{2 , 3 0 3})\end{array}$ & $\begin{array}{l}\operatorname{VITAL}(52) \\
(\mathbf{n}=\mathbf{2 5 , 8 7 4 )}\end{array}$ & $\begin{array}{l}\text { ViDA(24) } \\
(n=5,108)\end{array}$ \\
\hline \multicolumn{5}{|l|}{$\begin{array}{l}\text { participants taking vitamin } \\
\text { D supplements, IU/day }\end{array}$} \\
\hline $\begin{array}{l}\text { Participants taking calcium } \\
\text { supplements, } \%\end{array}$ & 33.0 & Not available & 26.4 & 4.9 \\
\hline $\begin{array}{l}\text { Calcium intake from } \\
\text { supplements among } \\
\text { participants taking calcium } \\
\text { supplements, mg/day }\end{array}$ & 311 & 600 & Not available & Not available \\
\hline Aspirin use \% & 24.7 & Not available & 45.4 & Not available \\
\hline
\end{tabular}

